\title{
Research on the Internet of Things Across the Road of the Stereo Garage Design
}

\author{
Hou Lun Yuan, Yang Guangming \\ Automobile Application Technology Department, Career Technical College of Hefei, Caohu, China
}

Email address:

990927801@qq.com (Hou Lun Yuan), 565954139@qq.com (Yang Guangming)

\section{To cite this article:}

Hou Lun Yuan, Yang Guangming.Research on the Internet of Things Across the Road of the Stereo Garage Design. Science Discovery. Vol. 5, No. 2, 2017, pp. 157-163. doi: 10.11648/j.sd.20170502.21

Received: April 5, 2017; Accepted: May 8, 2017; Published: May 11, 2017

\begin{abstract}
The purpose of this paper is to design a cross road networking intelligent stereo garage, can make full use of the space above the existing roads, improve space utilization, and equipped with a networking intelligent management system, through the intelligent car parked car stop system can realize the intelligent and automatic process, timely release of information through dynamic parking the Internet, efficient and convenient to improve the vehicle owner to stop taking, for garage managers can improve the management efficiency, reduce management costs, effectively guarantee the safety of vehicles. How to solve the parking problem in the limited space effectively, especially the parking problem in large cities, is of great significance to maintain the normal operation of urban traffic system and promote the development of urban economy.
\end{abstract}

Keywords: Across the Road, The Internet of Things, Intelligent, Parking Equipment

\section{物联网跨越道路式立体车库的设计研究}

侯伦元，杨光明

汽车应用技术系, 合肥职业技术学院, 巢湖, 中国

邮箱

990927801@qq. com（侯伦元），565954139@qq. com（杨光明）

摘要: 本文旨在设计研究一种跨越道路式物联网智能化立体车库, 可充分利用现有道路上方的空间, 提高空间利用率, 且搭载了物联网智能化管理系统, 通过智能停取车系统可实现停取车过程智能化、自动化, 通过互联网及时发布停车 库动态信息, 提高车主停取车辆的高效性、便捷性, 对于车库管理者而言可提高其管理效率, 节约管理成本, 有效保 障车辆安全。如何在有限的空间内解效解决好城市停车问题, 尤其是大型城市的停车问题, 对维护城市交通系统的正 常运作以及促进城市经济发展具有重要意义。

关键词：跨越道路, 物联网, 智能化, 立体停车库

\section{1. 引言}

近年来，随着城市经济持续快速发展，人们生活水平 的不断提高, 汽车进入家庭成为现实, 越来越多的城市居 民成为 “有车族” , 汽车给人们出行带来便利的同时, 也
产生了一系列的负面影响, 如交通阻塞、噪声污染、交通 事故以及交通环境污染, 更加恶化了原有的静态交通问题 - - 停车问题。如何在有限的空间内解效解决好城市停车 问题, 尤其是大型城市的停车问题, 对维护城市交通系统 的正常运作以及促进城市经济发展具有重要意义。本文将 对汽车激增所带来的的城市停车难问题进行探讨, 并研究 
设计一种物联网跨越道路式立体车库, 以期在一定程度上 缓解我国城市停车紧张的状态。[1]

\section{1. 国内外研究现状}

国家质量监督检验检疫总局颁布的《特种设备目录》 (国质检锅 [2004] 31 号) 中, 把机械式停车设备共分为 九大式, 代码4D10-4D90, 即: 升降横移式 (PSH), 垂直循 环式 (PCS)、多层循环式 (PDS)、平面移动式 (PPY)、巷道 堆垛式 (PXD) 、水平循环式 (PSX)、垂直升降式 (PCS)、简 易升降式(PJS)、汽车专用升降机式 (PQS)。总体来说, 目 前国内停车场产品成熟度较低, 技术水平和可靠性实际上 还不能满足更高的要求, 设备没有形成主流品牌, 能提供 成套设备的厂商更少, 用户在设备选型时存在困难。停车 场智能系统的市场现状比较落后, 大大落后于动态交通的 智能化市场发展。

这一点国内外都存在这样的问题, 过去的发展重动态 交通, 而轻静态交通, 比如静态交通研究目前国内外都没 有一个评价指标, 而动态交通则有道路拥堵指数、绿波带 等研究内容。静态交通发展的落后, 已经成为了城市动态 交通的障碍, 目前国内外的专家提出了解决动态交通要 “动静结合” “以静制动” 的理论, 在实践中已经初见成 效。未来静态交通智能化市场和动态交通智能化市场应该 平分秋色, 不分伯仲, 静态交通智能化市场的发展前景非 常大。[2]

\section{2. 现存问题分析}

\subsection{1. 占地面积过大}

汽车保有量的增加, 截至2016年6月底, 全国机动车 保有量达 3.21 亿辆, 全部露天平面停放, $S=1 * b$, 设普通 轿车长为 $4.5 \mathrm{~m}$, 宽为 $1.8 \mathrm{~m}$, 根据汽车最小转弯半径的计算 公式 $(R=L / 2(\operatorname{Sin} \psi) ; D=W+2 R(1-\operatorname{Cos} \psi)$; 式中: $R=$ 车 辆最小转弯半径; $\mathrm{L}=$ 车长; $\mathrm{W}=$ 车宽; $\mathrm{D}=$ 车辆最小转弯道宽 度; $\Psi=$ 车辆方向最大转角。) 则每辆轿车所需要的最小 停车位面积为 $19.2 \mathrm{~m}^{2}$ 。目前车辆将会占用 9600 万 $\mathrm{m}^{2}$ (即 90 万亩) 的土地。若在大中城市的核心地段建造室外停车 库, 会造成土地资源的浪费, 建造成本也会增加。如果改 为立体停放, 特别是高层立体车库, 每辆车的占用面积将 会大为降低, 例如, 10 层高的电梯式立体车库, 每辆车的 占用面积为 $3.0 \mathrm{~m}^{2}$ 左右, 将会节省 $84.6 \%$ (即 $18-24$ 万亩) 的土地, 即使有 $10 \%$ 的轿车停放在立体车库中, 这在大城 市的繁华地带也将产生巨大的经济效益。

\subsection{2. 停车管理混乱}

目前建立立体停车库数量过少, 而大多数汽车则停放 在露天停车场, 车位紧张, 占道停车现象十分严重, 影响 城市市容市貌, 影响交通顺畅, 造成交通拥堵, 从而引发 交通事故。且汽车露天放置有时会导致汽车偷窃、损毁等 事故, 车主经济财产安全得不到有效保障。有些停车场同 时需要配备多名管理员才能完成对车主的停取车辆的引 导、管理及收费等过程, 管理效率较低, 管理成本较高。 同时, 人工管理方式存在很多弊端, 由于收费人员素质不 同, 因此产生了大量的票款流失的现象, 据有关部门的保
守统计, 开放式停车场的票款流失率在 $20 \%-40 \%$, 从而 给国家和单位造成了较大的损失。另外, 在停车位资源十 分有限的情况下, 采用人工的管理方式, 很难做到使有限 的车位资源被充分地利用。

\subsection{3. 车库信息不畅}

现阶段大多停车场由于缺乏良好的信息管理、发布的 手段, 造成许多的停车场的使用率并不理想。车库信息得 不到实时共享, 停车诱导系统不完善等。同时, 由于缺少 准确的信息指引, 许多车主在寻找车位时常常要花费很长 的时间, 如上海港汇广场的停车场, 停车位置将近 1200 个, 偶尔停车的车主经常因为不清楚车场的位置以及车位 信息, 从而花上半个多小时来寻找能够停放车辆的地点。 车库空位信息得不到实时共享, 有时寻找到的停车场车位 已满, 停车效率很低。

针对上述问题可以设计研究一种跨越道路式物联网 智能化立体车库。

\section{2. 跨越道路式车库的设计研究思路}

\section{1 . 总体思路}

物联网跨越道路式立体车库分为车库本体设计研究 和物联网智能化管理系统设计研究, 车库本体可充分利用 现有道路上方的空间, 提高空间利用率, 在有限空间内实 现停车数量最大化; 搭载的物联网智能化管理系统, 通过 智能停取车系统可实现停取车过程智能化、自动化, 通过 互联网及时发布停车库动态信息, 提高车主停取车辆、管 理者管理车辆的高效性、便捷性、安全性。

\section{2. 车库本体设计思路}

物联网立体跨越道路式车库的车库本体是通过在道 路上方建造支撑桥梁体, 然后将具有若干层停车平台的车 库框架建造在支撑桥梁体上, 该车库的停车位在满足要求 的情况下排列组合紧凑, 能够充分利用现有道路上方的空 间, 提高空间利用率。在道路两侧分别建造一个提升机井 道, 利用提升机将横移平台、智能搬运器及车辆运输至指 定层的停车平台后, 横移平台带着智能搬运器及车辆在该 层的横移巷道上横向移动至指定停车位前, 最后智能搬运 器将车辆送入指定停车位上, 如此即可实现存车。此外每 个停车位也可以在计算机程序控制下快速移动到停车场 的出入口, 极大限度的提高了存取车辆的便捷性。

\section{3. 物联网智能化管理系统设计思路}

跨越道路式平面移动类立体车库将搭载物联网智能 化管理系统。车库本体开设有入库口和出库口, 入库口和 出库口均设置有闸机、智能刷卡机, ETC装置等; 具体涉 及一种物联网智能停车系统, 包括红外线光电传感器、无 线信号接收器、信号处理系统、无线网络和数据管理系统, 它们形成一个停车场网络监控系统; 通过一种物联网智能 停车系统, 管理员能及时指挥车主找到空车位, 车主手机 有关注微信公众号等线上方式即时了解车库空位信息, 找 到最近的空车位去停车。[8] 


\section{3. 跨越道路式立体车库机械设计}

\section{1. 设计结构}

包括立体车库架体、提升机、横移平台、智能搬运器, 智能搬运器设置在横移平台上, 立体车库架体包括横跨在 道路上方的支撑桥梁体、车库框架, 支撑桥梁体包括横向
分布在道路上方的桥面、若干个坚向分布的桥墩, 车库框 架固定在桥面上; 车库框架内固定有若干层停车平台, 各 层停车平台的中部均设有横移巷道, 横移巷道两侧各设有 若干个停车位; 立体车库架体两端分别固定有一提升机井 道, 提升机井道坚向分布地固定在横移巷道两端且与各层 横移巷道相连通, 提升机井道底端两侧均开设有车辆进出 口。如图1所示。

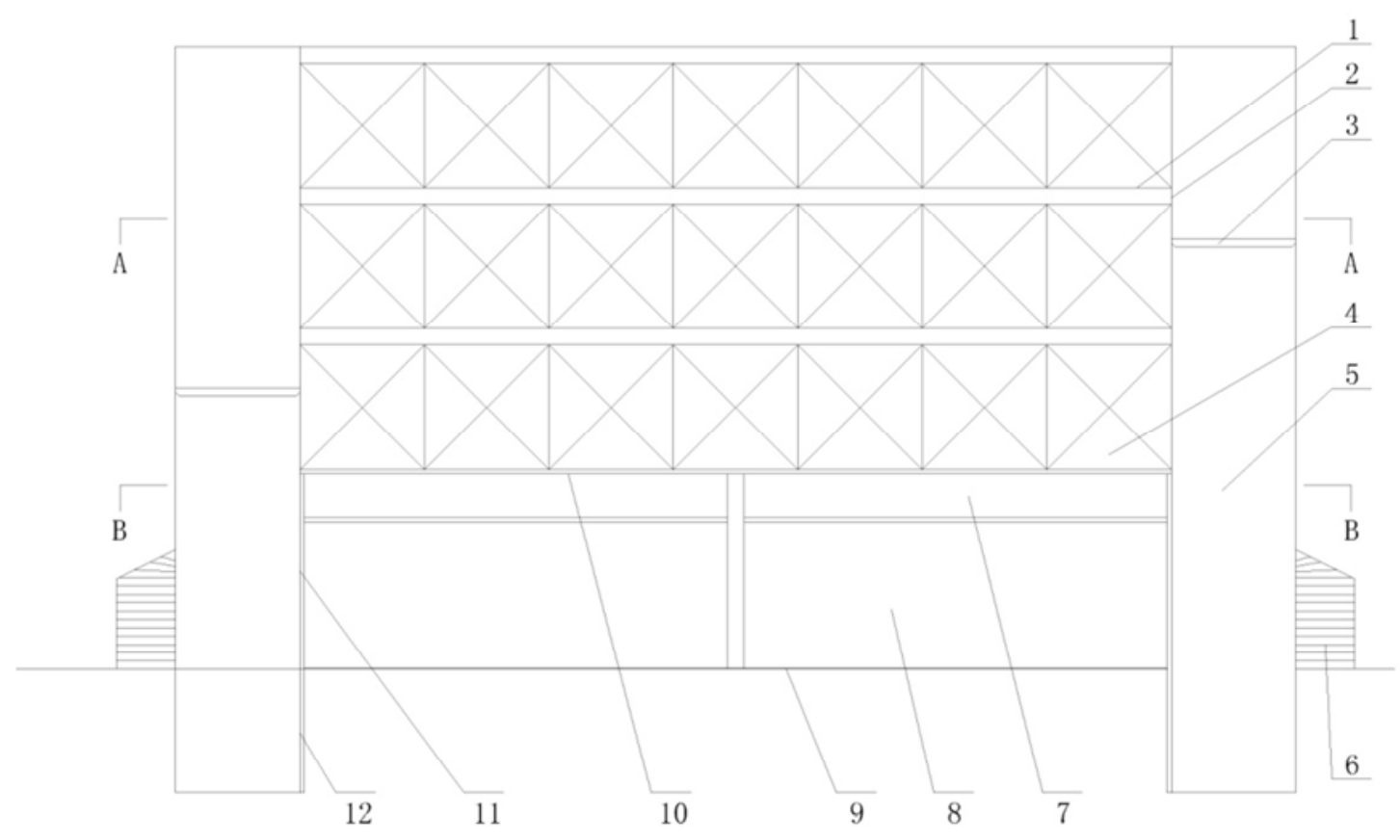

图1 结构示意图。

1-车库框架, 2-支撑桥梁体, 3-横移巷道, 4-停车位, 5-提升机井道, 6-扶梯, 7-人行通道室, 8-车辆行驶通道, 9-停车平台, 10-桥面, 11-桥墩, 12-地下一层井道室

\section{2. 设计传动路线}

跨道路式平面移动类立体车库，包括立体车库架体、 提升机、与停车位相对应的横移平台、用于取放车辆的智 能搬运器, 其中智能搬运器设置在横移平台上; 横移平台 设置在提升机上, 其特征在于: 立体车库架体包括横跨在 道路上方的支撑桥梁体、固定在支撑桥梁体上的车库框架; 支撑桥梁体包括横向分布在道路上方的桥面、若干个坚向 分布地用于支撑桥面的桥墩; 车库框架固定在桥面上, 车 库框架内固定有若干层停车平台, 各层停车平台的中部均 设有供横移平台横向往复运动的横移巷道, 两侧各设置有 若干个并排分布的停车位; 立体车库架体两端分别固定有 一供提升机上下升降移动的提升机井道, 提升机井道坚向 分布地固定在横移巷道两端且与各层横移巷道相连通, 提 升机井道底端两侧均开设有车辆进出口。

桥面底面上固定有人行通道室, 两端开设有出入口, 出入口处固定有扶梯, 扶梯环绕固定在提升机井道外侧壁 上; 人行通道室底面、道路表面与相邻两个桥墩共同围成 车辆行驶通道。
提升机井道对应的地下建造有地下一层井道室, 提升 机井道的底端延伸至地下一层井道室内, 地下一层井道室 两侧开设有与车辆进出口相对应的进出通道。

\section{3. 优化设计}

提升机井道对应的地下建造有地下一层井道室, 底端 延伸至地下一层井道室内, 井道室两侧开设有与车辆进出 口相对应的进出通道, 有效节省停车空间, 在有限的空间 内使停车数量最大化, 与传统停车库相比占地面积相差 20 余倍。基于计算机程序控制系统下运行速度快、维护方便, 采取电机驱动的方式, 节能环保。外部人员不能随意进入, 汽车不会受到人为损伤和丢失, 安全有保障, 防止车辆丢 失及损坏, 用完善的安全装置可保证汽车安然无恙。

\section{4. 具体实施方式}

为了使本方案车库本体设计的目的、技术方案及优点 更加清楚明白, 以下结合附图及实施例, 对本方案进行进 一步详细说明。 


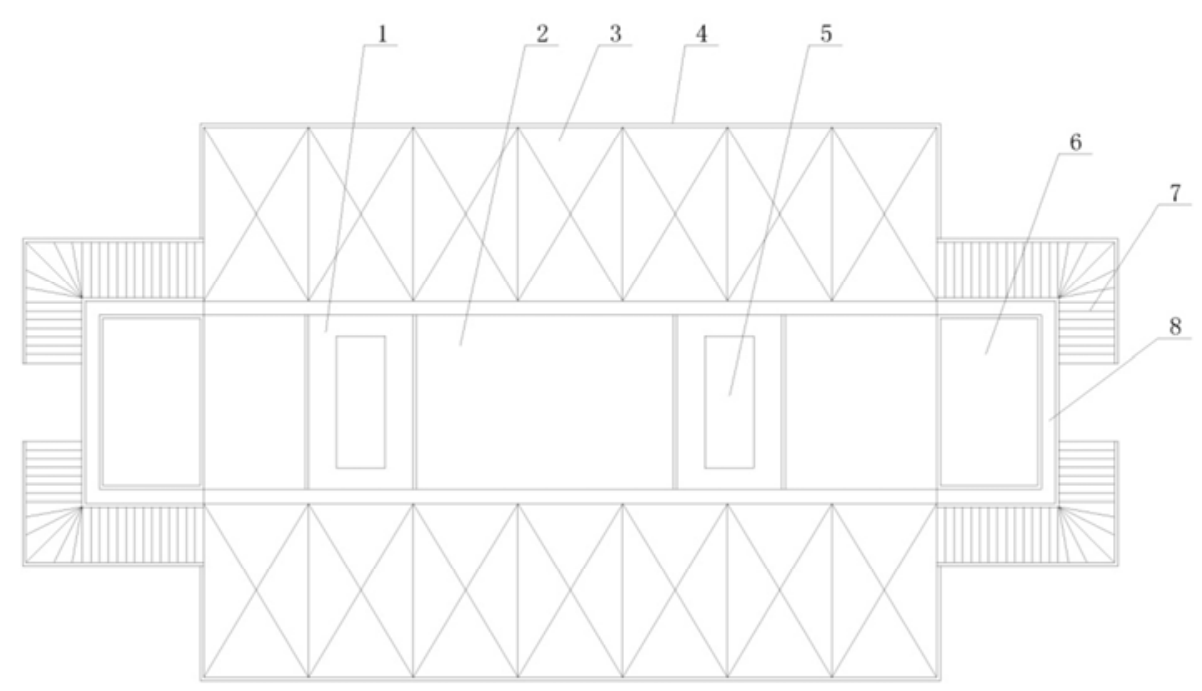

1-横移平台，2-横移巷道，3-停车位，4-车库框架，5-智能搬运器，6-提升机，7-扶梯，8-提升机井道 图2 中A-A向示意图。

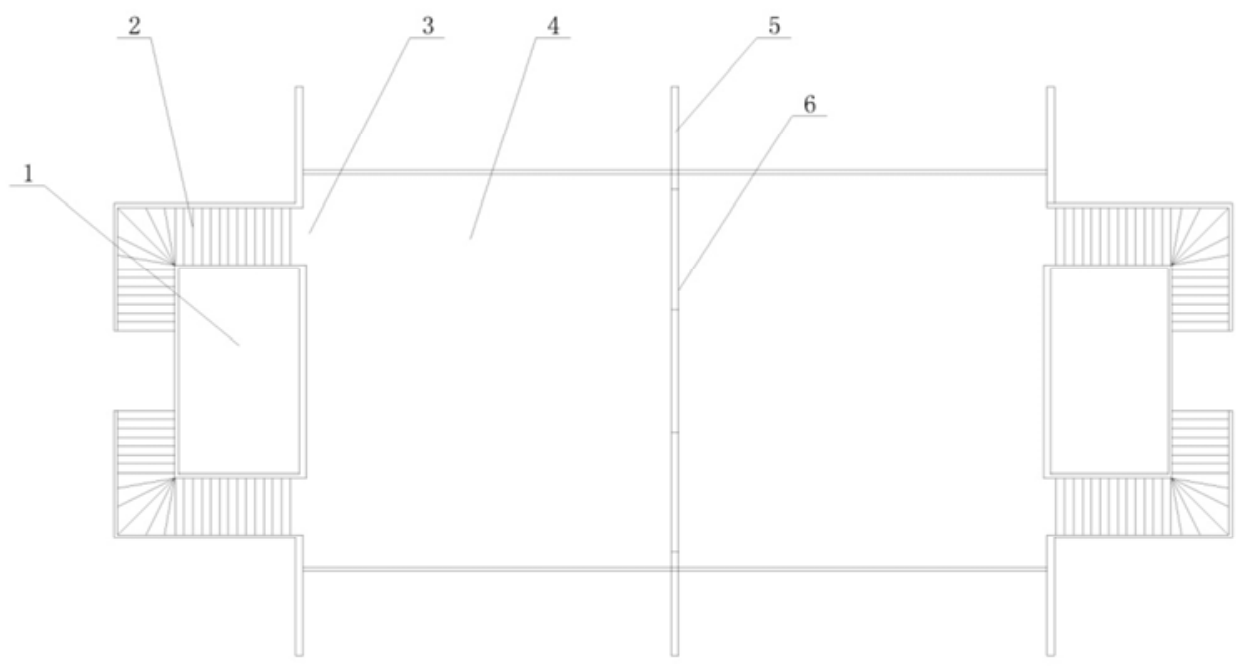

1-提升机井道, 2-扶梯, 3-出入口, 4-人行通道室, 5-桥墩, 6-开口

图3 中B-B向示意图。

\section{4.1. 车库立体结构}

参照图1至图3可知, 跨道路式平面移动类立体车库, 包括立体车库架体、提升机、与停车位相对应的横移平台、 用于取放车辆的智能搬运器, 智能搬运器设置在横移平台 上，横移平台设置在提升机上，立体车库架体包括横跨在 道路上方的支撑桥梁体、固定在支撑桥梁体上的车库框架。

支撑桥梁体包括横向分布在道路上方的桥面、三个竖 向分布地用于支撑桥面的桥墩。桥面底面上固定有人行通 道室, 人行通道室两端开设有出入口, 相邻两个桥墩之间 固定有一人行通道室, 中间桥墩开设有连通两个人行通道 室的开口, 出入口处固定有扶梯, 扶梯环绕固定在提升机 井道外侧壁上。人行通道室底面、道路表面与相邻两个桥 墩共同围成车辆行驶通道。
立体车库架体建造在现有道路的上方, 道路上行驶的 车辆可通过车辆行驶通道正常行驶。道路两侧的扶梯与人 行通道室配合, 起到传统人行天桥的功能, 方便行人通过 人行通道室走到道路另一侧。

车库本体框架固定在桥面上。车库框架内固定有若干 层停车平台, 各层停车平台的中部均设有供横移平台横向 往复运动的横移巷道, 横移巷道两侧各设置有若干个并排 分布的停车位。[10]

立体车库架体两端分别固定有一供提升机上下升降 移动的提升机井道, 提升机井道坚向分布地固定在横移巷 道两端且与各层横移巷道相连通, 提升机井道底端两侧均 开设有车辆进出口 (图中未示出)。为方便车辆进出立体 车库, 同时缓解车辆进出给道路交通带来的交通压力, 在 提升机井道对应的地下建造有地下一层井道室, 提升机井 道的底端延伸至地下一层井道室内, 地下一层井道室两侧 
开设有与车辆进出口相对应的进出通道 (图中未示出); 车辆通过地下一层井道室进出提升机井道实现存车或取 车。 $[3]$

\section{4. 2. 智能操作系统}

立体车库还包括用于控制车辆存取工作的智能操作 系统, 该智能操作系统包括PLC控制器、用于控制提升机 上下升降移动的提升机控制系统、用于控制横移平台在横 移巷道内横向往复移动的横移平台控制系统、用于控制智 能搬运器相对停车位取放车辆的智能搬运器控制系统, 该 提升机控制系统、横移平台控制系统、智能搬运器控制系 统均通过PLC控制器进行操作控制。

该智能操作系统的结构及工作原理、提升机在提升机 井道内的上下升降移动原理、横移平台在横移巷道内的横 向往复移动原理、智能搬运器存取车辆的原理均属于传统 平面移动类立体车库的现有技术，本文不再赘述。

车辆需要存放时, 通过PLC控制器操控提升机将至车 辆进出口, 将车辆置于提升机上, 再控制提升机上升至指 定层的停车平台, 然后通过PLC控制器操控横移平台带着 智能搬运器、车辆横移至指定停车位前停下, 再通过PLC 控制器操控智能搬运器将车辆放在指定的停车位上, 即可 实现车辆存放。需要取车时, 通过PLC控制器操控待取车 辆所在层的横移平台移动至对应的停车位前, 再通过智能 搬运器将车辆搬至横移平台上, 然后横移平台返回至提升
机上, 再操控提升机沿着提升机井道降下, 即可实现取车。 [4]

\section{4. 跨越道路式立体车库物联网智能化管理系统 设计}

\section{1. 结构设计}

物联网智能自动化停车库, 包括前文所述跨越道路式 平面移动类立体车库本体, 车库车位管理系统, 车库本体 开设有入库口和出库口, 入库口和出库口均设置有闸机、 用于控制闸机开启关闭的智能刷卡机或IC扫描机; 车库本 体内设置有若干排车位组, 各排车位组均由若干个停车位 组成, 各停车位的中央位置处均设置有一地磁感应车位检 测器, 感应车位检测器、路由节点单元、网关节点单元、 主控室管理平台, 地磁感应车位检测器用于判断对应停车 位的停车信息, 并通过无线传输方式传送给路由节点单元, 路由节点单元用于接收地磁感应车位检测器检测的停车 信息并通过无线传输方式发送至网关节点单元进行处理, 网关节点单元连接于主控室管理平台, 主控室管理平台设 有数据库、管理单元和LED显示屏; 智能刷卡机连接于主 控室管理平台。主控室管理平台通过互联网将车位信息发 送给交通广播电台。各排车位组均对应设置有一个电动汽 车移动式充电机器人。各停车位均对应设置有一个电动汽 车充电桩。[6]

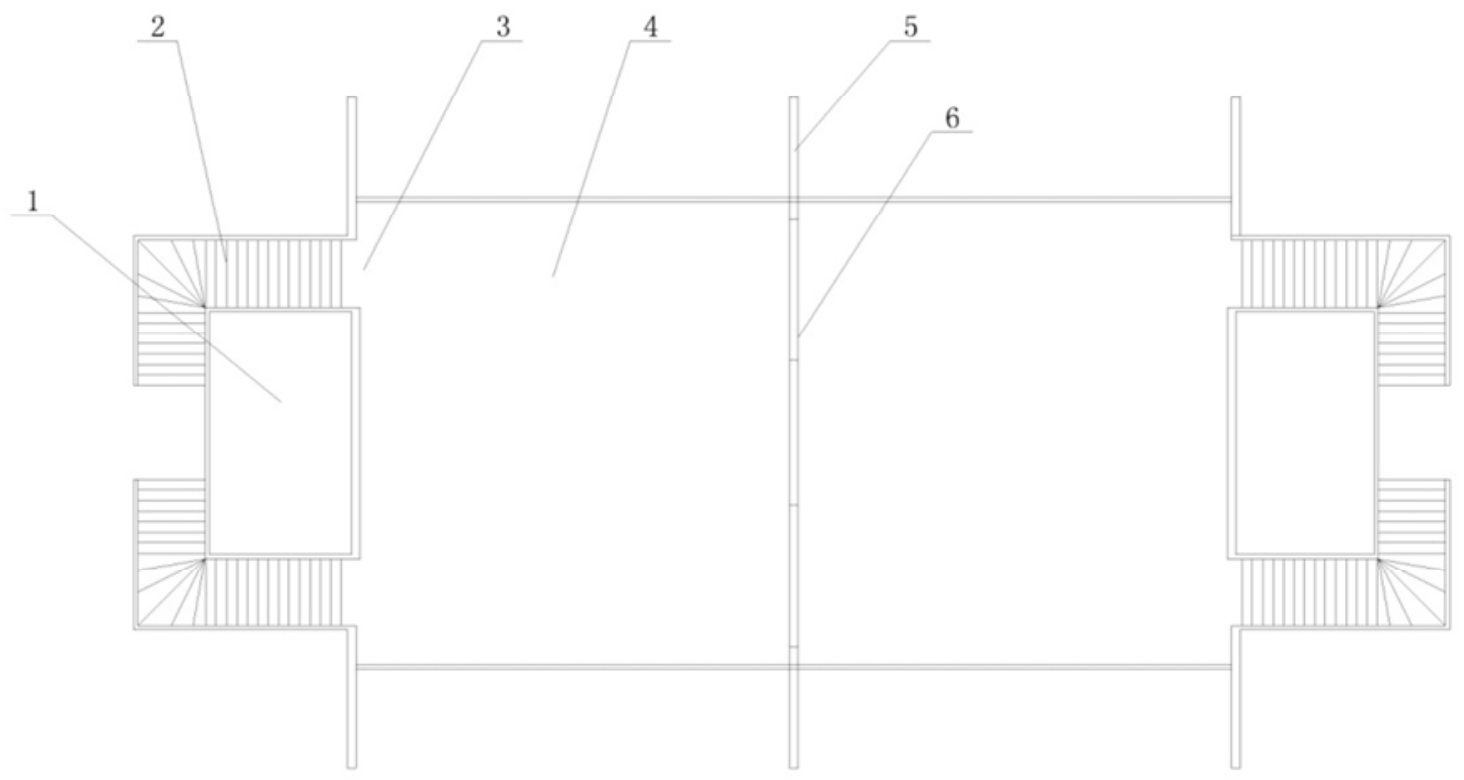

图4 结构示意图。

1-车库本体, 2-入库口, 3-出库口, 4-闸机, 5-智能刷卡机, 6-停车位, 7-地磁感应车位检测器, 8-路由节点单元, 9-网关节点单元, 10-主控室 管理平台, 11-数据库, 12-管理单元, 13-LED显示屏, 14-交通广播电台, 15-电动汽车移动式充电机器人, 16-电动汽车充电桩

\section{2. 车位管理系统工作原理}

红外线光电传感器 (10) 安装于每个停车位 (90) 上, 用于判断对应停车位的停车信息, 并传送到无线信号接收 器 (20)；无线信号接收器将接收的信号传送到信号处理
系统（30）; 信号处理系统对接收到信号进行处理，并将 模拟信号转换成所需要的数字信号和图像信号通过无线 网络 (40) 发送到数据管理系统 (50); 数据管理系统设 有数据库 (51)、管理单元 (52)、电子显示屏 (53) 及 微信公众号（54），如图5所示 


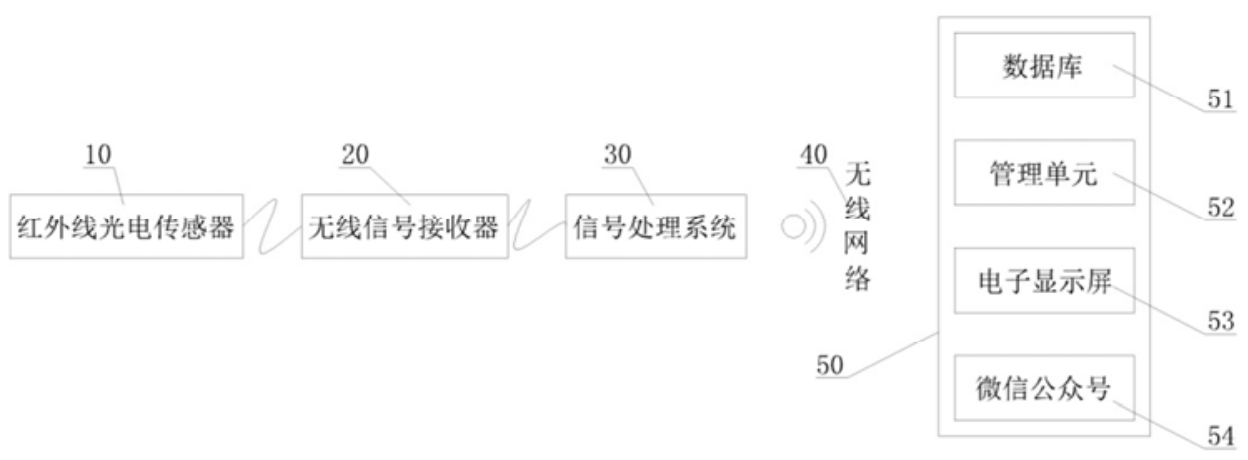

50-数据管理系统

图5 车库车位管理系统工作原理框图。

\section{3. 具体实施方式}

参照图4可知, 物联网智能自动化停车库, 包括车库 本体1、车库车位管理系统, 车库车位管理系统包括地磁 感应车位检测器 $7 、$ 路由节点单元 $8 、$ 网关节点单元 $9 、$ 主 控室管理平台 10 。

车库本体 1 开设有入库口 2 和出库口 3 , 入库口 2 和出库 口 3 均设置有闸机 4 、用于控制闸机 4 开启关闭的智能刷卡 机 5 , ; 智能刷卡机 5 连接于主控室管理平台 10 。本设计方 案提供的停车库, 其在车库的出库口 3 和入库口 2 都设置闸 机 4 和智能刷卡机 5 , 车主持卡对着智能刷卡机 5 刷一下, 闸机 4 便自动开启，等车辆通过后闸机 4 自动落下，智能刷 卡机5一方面用于控制闸机 4 , 另一方面也可以通过刷卡次 数记录车库进出车流量并传输给主控室管理平台 10 进行 储存便于工作人员管理。其中的闸机和智能刷卡机都属于 现有设备。[5]

车库本体 1 内设置有若干排车位组, 各排车位组均由 若干个停车位组成, 各停车位的中央位置处均设置有一地 磁感应车位检测器7; 地磁感应车位检测器7用于判断对应 停车位的停车信息, 并通过无线传输方式传送给路由节点 单元 8 , 路由节点单元 8 用于接收地磁感应车位检测器 7 检 测的车辆信息并通过无线传输方式发送至网关节点单元 9 进行处理, 网关节点单元 9 连接于主控室管理平台 10 , 主 控室管理平台 10 设有数据库 11 、管理单元 12 和LED显示屏 13 , 主控室管理平台 10 通过互联网将车位信息发送给交通 广播电台 14 。[7]

主控室管理平台 10 的数据库 11 能把数据存储起来, 管 理单元12就会根据信号来处理需要收费的情况, 和提供管 理人员想要知道的停车位信息, 便于管理; LED显示屏 13 能实时显示现场空车位情况, 引导车主快速找到空车位停 车, 交通广播电台 14 能把该停车库现场空车位信息传递给 车主, 更加方便车主停车, 当该停车库没有空车位时, 通 过交通广播电台发布消息, 避免不知情的车主还向该停车 库处开，有助于缓解停车库附近的交通拥堵。[9]

通过一种物联网智能化管理系统，管理员能及时指挥 车主找到空车位, 车主手机有关注微信公众号等互联网途 径, 也能知道停车场哪里有空车位, 找到最近的空车位去 停车, 大大提高了停车效率, 方便了管理人员管理停车场。

\section{4. 优化设计}

智能化程度高, 基于物联网智能化管理技术系统下的 停车库, 智能刷卡或 IC扫描机能实现存车, 取车的自动化。 与互联网 (电台) 联动, 将车库车位信息通过互联网或者 广播电台及时反馈给车主, 便于车主及时掌握车库中车位 信息, 及时准确的寻找到停车空位。

\section{5. 结论}

该研究成果能分利用现有道路上方的空间，节约宝贵 的土地资源, 在有限的空间内使停车数量最大化, 基于计 算机程序控制系统下运行速度快、维护方便, 车提高车主 停取车辆的高效性、便捷性, 对于车库管理者而言可提高 其管理效率, 节约管理成本, 有效保障车辆安全, 采取电 机驱动的方式, 节能环保。搭载的物联网智能化管理系统, 可实现车库信息及时共享, 存取车辆实现智能化、自动化, 有效缓解城市停车难的静态交通问题。

\section{致谢}

本文为安徽省高校自然科学研究项目: 《智能化立体 停车库的研究》阶段成果之一。

\section{参考文献}

[1] 杨路路, 钱军浅谈缓解城市停车难的关键性措施 [J]; 中国 市场；2010年第19期

[2] 马幼捷; 张海涛; 邵保福; 马云斌. 电子智能化立体车库 的研究现状与走向 $[J]$; 电气自动化; 2008年05期

［3］杜桂荣; 彭斌等. 多层升降横移式立体停车库的构和控制 系统 [J]; 起重机运输. 2002. (4)

[4] 马红麟. 基于PLC控制的升降横移式立体车库的研究与设计 [J]; 智能建筑城市与城市信息. 2007. (9) 
[5] 谢明; 程怀舟. 多层升降横移立体停车库计算机监控系统 研究 $[J]$; 机械与电子. 2004（9）.28-31

[6] 莫少尧. 李云飞. 基于物联网的城市停车位管理系统 [J]; 单片机与嵌入式系统应用. 2011。（5）.11-12

[7] 郭娟黎. 大型停车场综合管理系统方案设计 $[J]$. 建筑电气; 2012年06期
[8] 陈保国; 魏一鸣; 郭润平. 城市立体车库建设可持续发展 的思考 $[\mathrm{J}]$; 科技经济市场；2015年01期

[9] 冯立兴. 智能停车场管理系统的设计与实现 $[\mathrm{J}]$; 电脑知识 与技术；2010年30期

[10] 徐宁. 智能立体车库的应用与研究 $[J]$; 机电产品开发与创 新；2009年01期 